\title{
Solution for Peritoneal Dialysis Dosage
} Form

National Cancer Institute

\section{Source}

National Cancer Institute. Solution for Peritoneal Dialysis Dosage Form. NCI Thesaurus. Code C149926.

Liquid sterile preparation consisting of an aqueous solution containing electrolytes with a concentration close to the electrolytic composition of plasma and glucose in varying concentrations or other suitable osmotic agents, intended for intraperitoneal use as a dialysis solution. 